\title{
Kredit Usaha Mikro Kecil dan Menengah (Kinerja Penyaluran UMKM) oleh Perbankan di Indonesia periode Tahun 2013 - 2018
}

\author{
R.M.Tedy Aliudin \\ Universitas Bina Sarana Informatika \\ tedy69aliudin@gmail.com
}

\begin{abstract}
Micro, Small and Medium Enterprises have a very important role in the Indonesian economy, which has proven to be a pillar during the monetary crisis in 1998, where micro, small and medium enterprises were able to survive. However, in the Indonesian banking financing system, micro, small and medium enterprises still receive a very small portion compared to large / corporate businesses. Bank Indonesia has made a regulation regarding the achievement of the target of lending to micro, small and medium enterprises. A simple study needs to be conducted, whether the targets set by Bank Indonesia can be met by public banks in Indonesia.
\end{abstract}

Keyword: Micro, Small, and Medium Enterprises

\section{PENDAHULUAN}

Usaha Mikro, Kecil dan Menengah (UMKM) mempunyai peran penting dan strategis dalam pembangunan ekonomi nasional. Selain berperan dalam pertumbuhan ekonomi dan penyerapan tenaga kerja, UMKM juga berperan dalam mendistribusikan hasil-hasil pembangunan. UMKM juga telah terbukti tidak terpengaruh terhadap krisis. Ketika krisis menerpa pada periode tahun 1997 1998, hanya UMKM yang mampu tetap berdiri kokoh .(Naode, 2008)

Usaha Mikro, Kecil dan Menengah (UMKM) memberikan sumbangsih hampir $60 \%$ (enam puluh persen) atas Produk Domestik Bruto (PDB) dan $97 \%$ (sembilan puluh tujuh persen) penyerapan tenaga kerja(Suci, Tinggi, \& Ekonomi, 2017).

Melihat peran besar pelaku Usaha Mikro, Kecil dan Menengah (UMKM) tersebut, maka perlu diberikan porsi yang lebih besar lagi, sehingga banyak pihak mendesak baik pemerintah maupun legislatif, yang akhir menghasilkan Undang Undang nomor 20 tahun 2008, mengenai Usaha Mikro, Kecil dan Menengah (UMKM), sebagai payung hukum agar dapat bergerak lebih leluasa.

Lebih dari $99 \%$ pelaku usaha Indonesia merupakan Usaha Mikro, Kecil dan Menengah (UMKM), hanya sebagian kecil saja pelaku usaha besar/korporasi (Suci et al., 2017). Namun sebagian besar penyaluran kredit bank atau lebih dari $81 \%$ dari total penyaluran kredit diberikan kepada pelaku usaha besar/korporasi. Menyikapi hal tersebut, Bank Indonesia membuat suatu peraturan guna lebih memberikan porsi yang lebih besar didalam penyaluran kredit kepada pelaku Usaha Mikro, Kecil dan Menengah (UMKM) dengan menerbitkan Peraturan Bank Indonesia nomor 14/22/PBI/2012 (B. Indonesia, 2012) tentang pemberian kredit atau pembiayaan oleh bank umum dan bantuan teknis dalam rangka pengembangan Usaha Mikro, Kecil dan Menengah, dengan peraturan perubahan nomor
17/12/PBI.2015, bahwa bank wajib memberikan pembiayaan kepada pelaku Usaha Mikro, Kecil dan Menengah serendah-rendahnya $20 \%$ (dua puluh persen) yang dihitung berdasarkan rasio Kredit atau Pembiayaan UMKM terhadap total Kredit atau Pembiayaan. Pemenuhan kewajiban tersebut harus dilakukan oleh perbankan paling lambat tahun 2018, mengingat Bank Indonesia cukup memahami masih banyak bank yang belum memiliki skim kredit yang menunjang untuk UMKM.

\section{METODOLOGI PENELITIAN}

Jenis Penelitian yang dilakukan berbentuk deskriptif kuantitatif, dengan tujuan memberikan gambaran perkembangan dan pertumbuhan penyaluran kredit/pembiayaan kepada pelaku Usaha Mikro, Kecil dan Menengah secara menyeluruh.

Lokasi penelitian di kantor Bank Indonesia, Jakarta, dengan menggunakan teknik dokumentasi berupa data kinerja perbankan dari tahun 2013 sampai dengan bulan September 2018.

Langkah-langkah penilaian meliputi :

1. Menghitung pertumbuhan penyaluran kredit/pembiayaan oleh bank kepada nasabah pihak ketiga bukan bank secara umum.

2. Menghitung pertumbuhan penyaluran kredit/pembiayaan kepada pelaku Usaha Mikro, Kecil dan Menengah.

3. Menghitung ratio penyaluran kredit kepada pelaku Usaha Mikro, Kecil dan Menengah.

4. Menghitungan kualitas kredit/pembiyaan secara umum dan UMKM.

\section{A. Kredit}

UU No. 7 Tahun 1992 tentang Perbankan sebagaimana telah diubah dengan UU No. 10 Tahun 1998 (UU Perbankan) mendefinisikan kredit sebagai penyediaan uang atau tagihan yang dapat dipersamakan dengan itu, berdasarkan persetujuan atau kesepakatan pinjam meminjam antara bank dengan pihak lain yang mewajibkan pihak peminjam untuk melunasi utangnya setelah jangka waktu 
tertentu dengan pemberian bunga(P. R. Indonesia et al., 1991).

Selain pengertian mengenai Kredit sebagaimana dimaksud di atas, dalam Undang Undang Perbankan juga dikenal adanya Pembiayaan berdasarkan Prinsip Syariah yang merupakan bentuk penyediaan dana yang dilakukan oleh Bank yang melaksanakan kegiatan usaha berdasarkan prinsip syariah.

Pembiayaan berdasarkan Prinsip Syariah adalah penyediaan uang atau tagihan yang dapat dipersamakan dengan itu, berdasarkan persetujuan atau kesepakatan antara bank dengan pihak lain yang mewajibkan pihak yang dibiayai untuk mengembalikan uang atau tagihan tersebut setelah jangka waktu tertentu dengan imbalan atau bagi hasil.

B. Usaha Mikro, Kecil dan Menengah (UMKM) Karakteristik UMKM merupakan sifat atau kondisi faktual yang melekat pada aktiftas usaha maupun perilaku pengusaha yang bersangkutan dalam menjalankan bisnisnya(Bank \& LPPI, 2015). Karakteristik ini yang menjadi ciri pembeda antar pelaku usaha sesuai dengan skala usahanya. Menurut Bank Dunia, UMKM dapat dikelompokkan dalam tiga jenis(Bank \& LPPI, 2015), yaitu:

1. Usaha Mikro (jumlah karyawan 10 orang);

2. Usaha Kecil (jumlah karyawan 30 orang); dan

3. Usaha Menengah (jumlah karyawan hingga 300 orang).

Dalam perspektif usaha, UMKM diklasifkasikan dalam empat kelompok, yaitu:

1. UMKM sektor informal, contohnya pedagang kaki lima.

2. UMKM Mikro adalah para UMKM dengan kemampuan sifat pengrajin namun kurang memiliki jiwa kewirausahaan untuk mengembangkan usahanya.

3. Usaha Kecil Dinamis adalah kelompok UMKM yang mampu berwirausaha dengan menjalin kerjasama (menerima pekerjaan sub kontrak) dan ekspor.

4. Fast Moving Enterprise adalah UMKM yang mempunyai kewirausahaan yang cakap dan telah siap bertransformasi menjadi usaha besar.

Di Indonesia, Undang-Undang yang mengatur tentang Usaha Mikro, Kecil, dan Menengah (UMKM) adalah Undang-Undang Nomor 20 Tahun 2008. Dalam undang-undang tersebut UMKM dijelaskan sebagai: "Sebuah perusahaan yang digolongkan sebagai UMKM adalah perusahaan kecil yang dimiliki dan dikelola oleh seseorang atau dimiliki oleh sekelompok kecil orang dengan jumlah kekayaan dan pendapatan tertentu."

Kriteria Usaha Mikro adalah sebagai berikut:

1. Memiliki kekayaan bersih paling banyak Rp50.000.000,00 (lima puluh juta rupiah) tidak termasuk tanah dan bangunan tempat usaha; atau

2. Memiliki hasil penjualan tahunan paling banyak Rp300.000.000,00 (tiga ratus juta rupiah).

3. Kriteria Usaha Kecil adalah sebagai berikut:
4. Memiliki kekayaan bersih lebih dari Rp50.000.000,00 (lima puluh juta rupiah) sampai dengan paling banyak Rp500.000.000,00 (lima ratus juta rupiah) tidak termasuk tanah dan bangunan tempat usaha; atau

5. Memiliki hasil penjualan tahunan lebih dari Rp300.000.000,00 (tiga ratus juta rupiah) sampai dengan paling banyak Rp2.500.000.000,00 (dua milyar lima ratus juta rupiah).

6. Kriteria Usaha Menengah adalah sebagai berikut:

7. Memiliki kekayaan bersih lebih dari Rp500.000.000,00 (lima ratus juta rupiah) sampai dengan paling banyak Rp10.000.000.000,00 (sepuluh milyar rupiah) tidak termasuk tanah dan bangunan tempat usaha; atau

8. Memiliki hasil penjualan tahunan lebih dari Rp2.500.000.000,00 (dua milyar lima ratus juta rupiah) sampai dengan paling banyak Rp50.000.000.000,00 (lima puluh milyar rupiah).

C. Kualitas Kredit

Merupakan penggolongan nasabah debitur berdasarkan timbulnya tunggakan kewajiban, sesuai Peraturan Bank Indonesia nomor7/2/PBI/2005, yang terdiri dari 5 golongan yaitu(G. B. Indonesia, 2005) :

Tabel 1. Kriteria Kualitas Kredit 2005

\begin{tabular}{ccl}
\hline $\begin{array}{l}\text { Lama hari } \\
\text { tunggakan }\end{array}$ & Koll & \multicolumn{1}{c}{ Keterangan } \\
\hline 0 hari & 1 & Lancar \\
\hline $1-90$ hari & 2 & Dalam Perhatian \\
\hline $91-120$ hari & 3 & Kurang Lancar \\
\hline $121-180$ hari & 4 & Diragukan \\
\hline $\begin{array}{c}\text { Besar dari } 180 \\
\text { hari }\end{array}$ & 5 & Macet \\
$\begin{array}{c}\text { Sumber : https://www.bi.go.id } \\
\end{array}$
\end{tabular}

Berdasarkan data 1, maka bisa dikatakan bahwa kolektabiltas 3, 4, dan 5 adalah termasuk ke dalam kredit bermasalah yang biasa disebut dengan istilah Non Performing Loan (NPL)(Suci et al., 2017). Nilai NPL yang besar akan berdampak buruk didalam penilaian tingkat kesehatan perbankan.

D. Kinerja Penyaluran Kredit Perbankan Merupakan data pencapaian penyaluran kredit secara umum yang dilakukan oleh perbankan, yang didalam pembahasan ini meliputi pertumbuhan kredit secara umum, pertumbuhan kredit Usaha Mikro, Kecil dan Menangah, Ratio perbandingan antara kredit Usaha Mikro, Kecil dan Menengah terhadap total kredit serta Kualitas kredit, baik secara umum maupun kualitas kredit Usaha Mikro, Kecil dan Menengah. Terdapat beberapa analisa dan perhitungan didalam pengukuran kinerha penyaluran kredit, khususnya kredit kepada Usaha Mikro, Kecil dan Menengah 
meliputi :

1. Pertumbuhan Kredit secara umum

Merupakan pengukuran perkembangan kredit umum yang dilakukan perbankan secara nasional (Budiono, 2011).

Adapun rumus pertumbuhan kredit secara umum sebagai berikut :

$\underline{\text { Realisasi Kredit Umum Xn - X(n-1) }}$

Realisasi Kredit Umum Xn-1

Keterangan :

$\mathrm{Xn} \quad=$ Tahun yang dihitung

$\mathrm{X}(\mathrm{n}-1)=$ Tahun sebelumnya

2. Pertumbuhan Kredit UMKM

Merupakan pengukuran perkembangan kredit Usaha Mikro, Kecil dan Menengah (UMKM), perbankan secara nasional.

Adapun rumus perhitungan pertumbuhan kredit UMKM adalah sebagai berikut :

Realisasi Kredit UMKM Xn-X(n-1)

Realisasi Kredit UMKM X(n-1)

Keterangan :

$\mathrm{Xn} \quad=$ Tahun yang dihitung

$\mathrm{X}(\mathrm{n}-1)=$ Tahun sebelumnya

3. Ratio Kredit UMKM terhadap Total Kredit

Merupakan pengukuran persentase kredit UMKM terhadap total kredit umum.

Ratio Kredit UMKM = $\underline{\text { Realisasi Kredit UMKM Xn }}$ Realisasi Kredit UmumXn

Keterangan :

$\mathrm{Xn}=$ Tahun yang dihitung

4. Kualitas Kredit

Merupakan pengukuran kualitas kredit secara umum dan kualitas kredit UMKM.

Kualitas Kredit $=$ Realisasi NPL Kredit UMKM Xn

Umum Realisasi Total Kredit Umum Xn

Kualitas Kredit=Realisasi NPL Kredit UMKM Xn UMKM Realisasi Kredit UMKM Xn

Keterangan :

$\mathrm{Xn}=$ Tahun yang dihitung

\section{HASIL DAN PEMBAHASAN}

Pengukuran penyaluran kredit Usaha Mikro, Kecil dan Menengah (UMKM) dengan melihat penilaian pertumbuhan kredit umum, dan kualitas kredit, sebagai bagian dari penilaian kinerja perbankan didalam penyaluran kredit ke pelaku UMKM secara nasional. Ratio kredit UMKM sesuai peraturan Bank Indonesia diwajibkan serendah-rendahnya adalah $20 \%$ dari total kredit. Semakin tinggi ratio, maka penilaian semakin baik. Apabila ratio kredit Usaha Mikro, Kecil dan menengah (UMKM) dibawah standar peraturan Bank Indonesia, maka akan dilihat salah satu faktor penyebabnya adalah kualitas kredit baik secara umum maupun kualitas kredit Usaha Mikro, Kecil dan Menengah (UMKM). Dari sisi nilai besaran maksimal kredit yang diberikan, setiap bank memiliki perbedaan dalam penentuan maksimum kredit untuk Usaha Mikro, Kecil dan Menengah (UMKM), namun penetapan kredit Usaha Mikro,
Kecil dan menengah (UMKM) lebih didasarkan pada katagori pelaku usaha tersebut sesuai dengan Undang Undang nomor 20 tahun 2008, mengenai Usaha Mikro, Kecil dan Menengah (UMKM).

1. Pertumbuhan kredit secara umum

Pertumbuhan kredit secara umum, semakin meningkat atau konsisten, maka penilaian akan semakin baik.

Tabel 2. Pertumbuhan Kredit Umum (Rp milyar)

\begin{tabular}{ccc}
\hline \multicolumn{1}{l}{ Tahun } & Jumlah & Pertumbuhan \\
\hline 2013 & 3.292 .874 & \\
\hline 2014 & 3.674 .308 & $11,58 \%$ \\
\hline 2015 & 4.057 .904 & $10,44 \%$ \\
\hline 2016 & 4.377 .195 & $7,87 \%$ \\
\hline 2017 & 4.737 .944 & $8,24 \%$ \\
\hline Sep 2018 & 5.120 .099 & $8,07 \%$ \\
\hline
\end{tabular}

Sumber : https://www.ojk.go.id Statistika Perbankan Indonesia 2018(Otoritas Jasa Keuangan, 2019)

Pertumbuhan rata-rata dalam 5 tahun adalah sebesar $9,24 \%$, dimana dalam 2 tahun terakhir berada dibawah pertumbuhan rata-rata kredit secara umum.

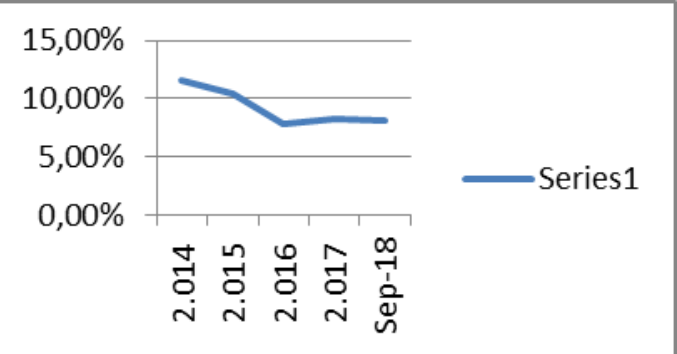

Sumber : https://www.ojk.go.id Statistika Perbankan Indonesia 2018

Gambar 1. Pertumbuhan Kredit Umum

Dari tabel 2 terlihat bahwa dalam 5 tahun terakhir, terjadi penurunan pertumbuhan kredit secara konsisten. Hal ini berdampak kurang baik dalam pertumbuhan ekonomi Indonesia secara menyeluruh.

\section{Pertumbuhan Kredit UMKM}

Merupakan perhitungan atas pertumbuhan kredit Usaha Mikro, Kecil dan Menengah (UMKM), yang dihitung dari tahun 2013 sampai dengan September 2018 (Agus Budiono, 2011).

Tabel 3. Pertumbuhan Kredit UMKM (Rp Milyar)

\begin{tabular}{ccc}
\hline Tahun & Jumlah & Pertumbuhan \\
\hline 2013 & 608.823 & \\
\hline 2014 & 671.721 & $10,33 \%$ \\
\hline 2015 & 739.801 & $10,14 \%$ \\
\hline 2016 & 802.113 & $8,42 \%$ \\
\hline 2017 & 882.982 & $10,08 \%$ \\
\hline Sep 2018 & 925.451 & $4,81 \%$ \\
\hline
\end{tabular}

Sumber : https://www.ojk.go.id Statistika Perbankan Indonesia 2018 
Pertumbuhan kredit UMKM secara rata-rata dalam 5 tahun adalah sebsar 8,76\%, dimana pada September 2018, pertumbuhan berada dibawah pertumbuhan rata-rata.

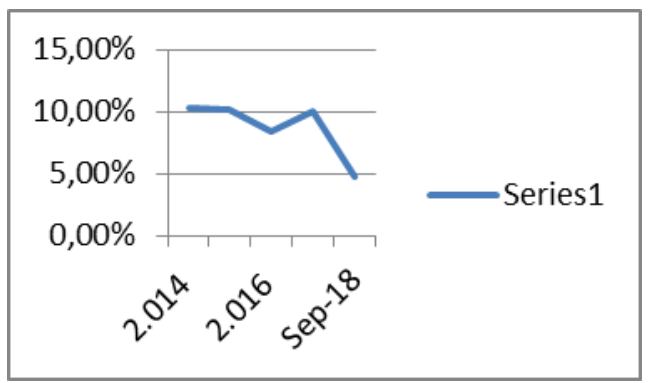

Sumber : https://www.ojk.go.id Statistika Perbankan Indonesia 2018

Gambar 2. Pertumbuhan Kredit UMKM

Dari table 3 pertumbuhan tersebut terlihat bahwa pertembuhan kredit UMKM cenderung menurun, berbanding lurus dengan pertumbuhan kredit secara umum.

\section{Ratio Kredit UMKM}

Merupakan perhitungan perbanding realisasi kredit UMKM terhadap total kredit secara umum, dimana sesuai peraturan Bank Indonesia minimal 20\%.

Tabel 4. Ratio Kredit UMKM (Rp Milyar)

\begin{tabular}{cccc}
\hline Tahun & Realisasi & Total Kredit & Ratio \\
\hline 2013 & 608.823 & 3.292 .874 & $18,49 \%$ \\
\hline 2014 & 671.721 & 3.674 .308 & $18,28 \%$ \\
\hline 2015 & 739.801 & 4.057 .904 & $18,23 \%$ \\
\hline 2016 & 802.113 & 4.377 .195 & $18,32 \%$ \\
\hline 2017 & 882.982 & 4.737 .944 & $18,64 \%$ \\
\hline Sep 2018 & 925.451 & 5.120 .099 & $18,07 \%$ \\
\hline
\end{tabular}

Sumber : https://www.ojk.go.id Statistika Perbankan Indonesia 2018

Dari data tersebut, terlihat bahwa ratio kredit UMKM masih dibawah $20 \%$ atau belum mencapai sesuai peratutan Bank Indonesia. Bahkan pada September 2018, ratio kredit kepada pelaku Usaha Mikro, Kecil dan Menengah (UMKM) dibawah ratio tahun 2013.

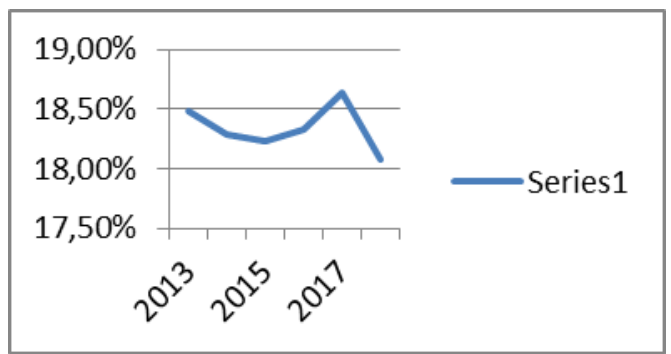

Sumber : https://www.ojk.go.id Statistika Perbankan Indonesia 2018

Gambar 3. Ratio Kredit UMKM

Dari tabel tersebut, terlihat bahwa pertumbuhan ratio kredit UMKM dominan menurun, meskpiun pada tahun 2017, sempat meningkat dibanding tahun tahun sebelumnya, namun pertumbuhan kembali menurun ditahun 2018 (September 2018).

4. Kulitas Kredit Umum dan UMKM

Kualitas kredit secara total/umum merupakan perbanding antara realisasi kredit yang berada diposisi NPL dibandingkan dengan total realisasi kredit umum.

Tabel 5. Kualitas Kredit Umum (Rp Milyar)

\begin{tabular}{cccc}
\hline Tahun & Realisasi & NPL & \%NPL \\
\hline 2013 & 3.292 .874 & 58.279 & $1,77 \%$ \\
\hline 2014 & 3.674 .308 & 79.388 & $2,16 \%$ \\
\hline 2015 & 4.057 .904 & 100.933 & $2,49 \%$ \\
\hline 2016 & 4.377 .195 & 128.135 & $2,93 \%$ \\
\hline 2017 & 4.737 .944 & 122.922 & $2,58 \%$ \\
\hline Sep 2018 & 5.120 .099 & 136.061 & $2,66 \%$ \\
\hline
\end{tabular}

Sumber : Sumber : https://www.ojk.go.id Statistika Perbankan Indonesia 2018

Kualitas kredit secara umum masih sangat baik, dibawah ketentuan peratusan Bank Indonesia, dimana kuliatas kredit dibawah 5\%, menunjukkan kondisi perbankan masih sehat.

Kulaitas kredit Usaha Mikro, Kecil dan Menengah adalah sebagai berikut :

Tabel 6. Kualitas Kredit UMKM (Rp milyar)

\begin{tabular}{cccc}
\hline Tahun & Realisasi & NPL & \%NPL \\
\hline 2013 & 608.823 & 19.515 & $3,21 \%$ \\
\hline 2014 & 671.721 & 25.159 & $3,75 \%$ \\
\hline 2015 & 739.801 & 29.792 & $4,03 \%$ \\
\hline 2016 & 802.113 & 31.734 & $3,96 \%$ \\
\hline 2017 & 882.982 & 35.178 & $3,98 \%$ \\
\hline Sep 2018 & 925.451 & 35.674 & $3,85 \%$ \\
\hline
\end{tabular}

Sumber : Sumber : Sumber : https://www.ojk.go.id Statistika Perbankan Indonesia 2018

Dari data kedua kualitas kredit, baik untuk kredit secara umum maupun kredit Usaha Mikro, Kecil dan Menengah (UMKM), dalam 6 (enam) tahun terakhir, rata-rata nilai Non Perfoming Loan (NPL) kredit secara umum total sebesar $2,43 \%$, sementara untuk Non Perfoming Loan (NPL) Kredit Usaha Mikro, Kecil dan Menengah (UMKM) sebesar 3,80\%, lebih besar dibandingkan dengan nilai Non Perfoming Loan (NPL) kredit secara umum. Non Perfoming Loan (NPL) Kredit Usaha Mikro, Kecil dan Menengah memang cukup mengkhawatirkan, meskipun masih dibawah syarat maksimal Non Perfoming Loan (NPL) yang disyaratkan oleh Bank Indonesia yaitu maksimal $5 \%$, dapat dipastikan bahwa salah satu yang menyebabkan perlambatan pengucuran kredit Usaha Mikro, Kecil dan Menengah (UMKM) adalah masih tingginya Non Perfoming Loan (NPL) kredit Usaha Mikro, Kecil dan Menengah (UMKM). 


\section{KESIMPULAN}

Pertumbuhan kredit perbankan nasional, secara umum rata-rata dalam 5 tahun terakhur sebesar 9,24\%, dan pertumbuhan kredit Usaha Mikro, Kecil dan Menengah (UMKM), rata-rata dalam 5 tahun terakhir sebesar $8,76 \%$ mengalami pertumbuhan yang cenderung menurun dari tahun ke tahun. Belum ada penelitian atau analisa yang dapat menjadi acuan, namun dari hasil diskusi dengan beberapa pelaku ekonomi bahwa pertumbuhan kredit cukup signifikan mempengaruhi pertumbuhan ekonomi secara umum. Seperti yang dapat kita rasakan bersama baha dalam 4 sampai dengan 5 tahun terakhir, terjadi pelemahan ekonomi dan bahkan pertumbuhan ekonomi Indonesia belum mencapai sesuai target yang ditetapkan.

Sementara ratio kredit kepada pelaku Usaha Mikro, Kecil dan Menengah (UMKM), masih dibawah 20\% dan bahkan cenderung menurun.

Bank Indonesia mengeluarkan peraturan pada tahun 2012 yang diperbaharui pada tahun 2015 yaitu Peraturan Bank Indonesia nomor 14/22/PBI/2012 tentang pemberian kredit atau pembiayaan oleh bank umum dan bantuan teknis dalam rangka pengembangan Usaha Mikro, Kecil dan Menengah, dengan peraturan perubahan nomor 17/12/PBI.2015, bahwa bank wajib memberikan pembiayaan kepada pelaku Usaha Mikro, Kecil dan Menengah serendahrendahnya $20 \%$ (dua puluh persen) yang dihitung berdasarkan rasio Kredit atau Pembiayaan UMKM terhadap total Kredit atau Pembiayaan. Namun sampai dengan September 2018, ratio kredit Usaha Mikro, Kecil dan Menengah masih berada dibawah $20 \%$ yaitu sebesar $18,07 \%$, bahkan dibawah ratio kredit UMKM ditahun-tahun sebelumnya.

Dari sisi kualitas kredit, dimana secara kredit umum, masih sangat baik, berada dibawah 5\% dari kebijakan batas maksimal tingkat kesehatan perbankan, dimana pergerakan kualitas kredit cukup konsisten, namun untuk kredit Usaha Mikro, Kecil dan Menengah (UMKM) berada diatas rata-rata kualitas kredit secara umum. Hal ini menunjukkan bahwa Kredit UMKM memiliki risiko yang lebih tinggi dibanding kredit usaha besar/korporasi.

Sesuai Pasal 12 Peraturan Bank Indonesia nomor 17/12/PBI.2015, apabila bank tidak mencapai ratio penyaluran kredit minimal 20\% dari total kredit, maka dikenakan pinalti untuk memberikan biaya pelatihan sebesar maksimal Rp 10.000.000.000,(sepuluh milyar rupiah) dan beberapa pinalti lainnya. Data ratio kredit Usaha Mikro, Kecil dan Menengah (UMKM) tersebut terakhir diambil pada bulan September 2018, namun dari trend pertumbuhan yang ada, dapat diyakini bahwa ratio kredit Usaha Mikro, Kecil dan Menengah (UMKM) masih diperkirakan dibawah $20 \%$ atau masih dibawah target sesuai peratutan Bank Indonesia yaitu minimal 20\%(G. B. Indonesia, 2015).

Data tersebut berdasarkan kinerja perbankan secara menyeluruh, namun dapat diyakini bahwa ada beberapa perbankan yang dapat mencapai ratio kredit Usaha Mikro, Kecil dan Menengah (UMKM) melebihi ambang minimal 20\%, namun tidak sedikit yang masih dibawah $20 \%$. Hal ini selain dipengaruhi kualitas kredit UMKM dengan risiko yang cukup tinggi dibanding kredit secara umum, juga faktor penunjang sumber daya yang belum semua bank memilikinya, seperti jaringan pemasaran, dimana pelaku UMKM dominan berada di pedesaan.

Bank Badan Usaha Milik Negra yang terdiri dari Bank BRI, Bank BNI, Bank Mandiri dan Bank BTN, dapat diyakini telah melampaui batas minimal ratio kredit kepada pelaku Usaha Mikro, Kecil dan Menengah (UMKM) karena telah memiliki jaringan pasar yang cukup baik di berbagai daerah di Indonesia, selain sumber daya dan tenaga yang banyak. Selain juga adanya program pemerintah dalam pengucuran kredit kepada pelaku Usaha Mikro, Kecil dan Menengah (UMKM) yaitu Kredir Usaha Rakyat (KUR) hanya diberikan kepada bankbank tertentu saja, yaitu Bank BUMN, Bank Pembangunan Daerah dan bank lainnya.

\section{REFERENSI}

Bank, I., \& LPPI. (2015). Profil Bisnis Usaha Mikro, Kecil dan Menengah (umkm). Bank Indonesia Dan LPPI, 1-138.

Budiono, A. (2011). Faktor-Faktor Yang Mempengaruhi Pertumbuhan Kredit Bank Umum Swasta Nasional (BUSN) di Indonesia.

Indonesia, B. (2012). Peraturan Bank Indonesia Nomor 14/22/PBI/2012 Tentang Pemberian Kredit UMKM.

Indonesia, G. B. (2005). Peraturan Bank Indonesia nomor $7 / 2 / \mathrm{PBI} / 2005$.

Indonesia, G. B. (2015). Peraturan Bank Indonesia 1712 PBI 2015, 1-13.

Indonesia, P. R., Presiden, K. K., Indonesia, R., Presiden, K. K., Indonesia, R., Terpadu, P. E., ... Daerah, P. O. (1991). Presiden Republik Indonesia, 2010(1), 1-5.

Naode, I. Y. (2008). Perkembangan Dan Strategi Memberdayakan Usaha Mikro Kecil Dan Menengah ( UMKM ). Jurnal FORMAS: Media Informasi \& Komunikasi Ilmiah Mahasiswa-Masyarakat, 1(4), 1-12.

Otoritas Jasa Keuangan. (2019). Statistika Perbankan Indonesia September 2018.

Suci, Y. R., Tinggi, S., \& Ekonomi, I. (2017). PERKEMBANGAN UMKM ( USAHA MIKRO KECIL DAN MENENGAH ) DI INDONESIA. Jurnal Ilmiah Fakultasi Ekonomi, 6(1), 51-58. https://doi.org/10.30606/CE.V6I1.1239

Bank, I., \& LPPI. (2015). Profil Bisnis Usaha Mikro, Kecil dan Menengah (umkm). Bank Indonesia Dan LPPI, 1-138. 
Budiono, A. (2011). Faktor-Faktor Yang Mempengaruhi Pertumbuhan Kredit Bank Umum Swasta Nasional (BUSN) di Indonesia.

Indonesia, B. (2012). Peraturan Bank Indonesia Nomor 14/22/PBI/2012 Tentang Pemberian Kredit UMKM.

Indonesia, G. B. (2005). Peraturan Bank Indonesia nomor 7/2/PBI/2005.

Indonesia, G. B. (2015). Peraturan Bank Indonesia 1712 PBI 2015, 1-13.

Indonesia, P. R., Presiden, K. K., Indonesia, R., Presiden, K. K., Indonesia, R., Terpadu, P. E., ... Daerah, P. O. (1991). Presiden Republik Indonesia, 2010(1), 1-5.

Naode, I. Y. (2008). Perkembangan Dan Strategi Memberdayakan Usaha Mikro Kecil Dan Menengah ( UMKM ). Jurnal FORMAS: Media Informasi \& Komunikasi Ilmiah Mahasiswa-Masyarakat, 1(4), 1-12.

Otoritas Jasa Keuangan. (2019). Statistika
Perbankan Indonesia September 2018.

Suci, Y. R., Tinggi, S., \& Ekonomi, I. (2017). PERKEMBANGAN UMKM ( USAHA MIKRO KECIL DAN MENENGAH ) DI INDONESIA. Jurnal Ilmiah Fakultasi Ekonomi, 6(1), 51-58. https://doi.org/10.30606/CE.V6I1.1239

\section{PROFIL PENULIS}

R.M.Tedy Aliudin, S.Si, MM, lahir di Tebing Tinggi, Sumatera Selatan, menyelesaikan S1 di Fakultas Matematikan dan Ilmu Pengetahuan Alam (MIPA), jurusan Matematika, Universitas Sriwijaya dan S2 di Magister Manajemen Unversitas Bandar Lampung (UBL). Pernah bekerja di Bank BNI dibagian kredit, dan saat ini aktif sebagai dosen di Universitas Bina Sarana Informatika (BSI) sejak tahun 2015 dan juga sebagai Ketua Lembaga Pengembangan Usaha kadin Indonesia. 